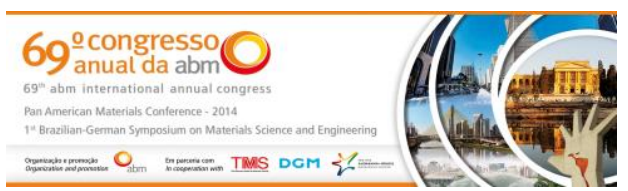

Tema: Corrosão

\title{
RESISTÊNCIA À CORROSÃO DOS AÇOS INOXIDÁVEIS SUPER DUPLEX ASTM A 890/A 890M GRAU 5A E 6A*
}

\section{Resumo}

Alessandra Souza Martins ${ }^{1}$ Marcelo Martins ${ }^{2}$ Walney Silva Araújo ${ }^{3}$

O aço inoxidável super duplex vem apresentando um desempenho satisfatório em ambientes de maior agressividade. Esse tipo de aço possui boas propriedades de resistência mecânica, resistência à corrosão e tenacidade ao impacto. Entretanto, mesmo apresentando desempenho satisfatório, esses aços podem apresentar problemas de corrosão quando sofrem algum tratamento térmico, devido à precipitação de uma fase deletéria chamada de alfa linha ( $\left.\alpha^{\prime}\right)$, a qual precipita em temperaturas entre $300^{\circ} \mathrm{C}$ e $550^{\circ} \mathrm{C}$ e pode ocasionar uma diminuição da resistência à corrosão e tenacidade do material. Portanto, o objetivo deste trabalho é avaliar a resistência à corrosão dos aços inoxidáveis super duplex de grau $5 \mathrm{~A}$ e $6 \mathrm{~A}$ após sofrerem tratamento térmico a $475^{\circ} \mathrm{C}$. A diferença entre os aços de grau 5A e 6A ocorre na presença de cobre e tungstênio na composição química do aço com grau $6 \mathrm{~A}$. A resistência à corrosão dos corpos de prova foi avaliada por meio das seguintes técnicas eletroquímicas: polarização anódica, espectroscopia de impedância eletroquímica e temperatura crítica de pite. A resistência mecânica dos corpos de prova foi avaliada por meio da técnica de dureza Brinell. Foi realizada também a caraterização microestrutural e a quantificação das fases do material. Os resultados mostraram um aumento da dureza do material, indicando um aumento da presença da fase $\alpha$ ' com 10 horas de tratamento térmico apresentaram maior resistência à corrosão.

Palavras-chave: Aço inoxidável; Super duplex; Corrosão.

\section{CORROSION RESISTANCE OF SUPER DUPLEX STAINLESS STEEL ASTM A 890 / A} 890M GRADE 5A AND 6A

\begin{abstract}
The super duplex stainless steel is widely used in aggressive corrosion environments. This type of steel has attractive combination of good mechanical strength in addition to excellent corrosion and impact resistance. However, when undergoing a heat treatment in temperature range between $300^{\circ} \mathrm{C}$ and $550^{\circ} \mathrm{C}$ a precipitation of $\alpha^{\prime}$-phase can occur causing a reduction of corrosion resistance and ductility. Therefore, the aim of this study is to evaluate the corrosion resistance of super duplex stainless steel grade $5 \mathrm{~A}$ and $6 \mathrm{~A}$ after heat treatment at $475^{\circ} \mathrm{C}$ for different aging time. The difference in chemical composition between these steel grades is copper and tungsten content. The corrosion resistance of the samples was evaluated employing following electrochemical techniques: open circuit potential measurement, anodic polarization, cyclic polarization, electrochemical impedance spectroscopy and critical pitting temperature. The electrochemical results indicate a strong influence of aging time on corrosion resistance. Microstructural examination revealed a dual phase structure composed of a ferritic matrix with austenite islands in equal proportion. The hardness increases rapidly in the early hours of heat treatment, then with progressing time the hardening rate decreases.

Keywords: Stainless steel; Super duplex; Corrosion.

Engenheira Química, graduada, mestranda, Programa de Engenharia e Ciência de Materiais, Universidade Federal do Ceará, Fortaleza, CE, Brasil.

2 Engenheiro de Materiais, Doutor, Gerente Industrial, Sulzer Brasil S.A., Americana, SP, Brasil.

3 Engenheiro Químico, Doutor, Professor do Departamento de Engenharia Metalúrgica e de Materiais, Universidade Federal do Ceará, Fortaleza, CE, Brasil.
\end{abstract}

\footnotetext{
* Contribuição técnica ao $69^{\circ}$ Congresso Anual da ABM - Internacional e ao 14ํㅡㄹ ENEMET - Encontro Nacional de Estudantes de Engenharia Metalúrgica, de Materiais e de Minas,21 a 25 de julho de 2014, São Paulo, SP, Brasil.
} 


\section{INTRODUÇÃO}

A corrosão tem sido um grande desafio para a ciência ao longo dos anos, pois ela é um fenômeno natural que ocorre nos materiais desde o começo da sua fabricação até o final de sua vida útil. Por isso, nos últimos anos, a Engenharia está investindo na pesquisa de novos materiais cada vez mais resistentes para suprir a grande demanda das novas tecnologias [1].

Um exemplo disso é a extração de petróleo da camada pré-sal no Brasil, que possui uma camada de sal que pode chegar a $2000 \mathrm{~m}$ de espessura, totalizando até $7000 \mathrm{~m}$ de profundidade. Então, percebe-se que existem dois grandes gargalos para a indústria petroquímica e plataformas offshore, que é encontrar um material que seja resistente à corrosão e também que tenha uma boa resistência mecânica [2,3]. Para esse tipo de situação os aços inoxidáveis tradicionais não são tão eficientes.

Uma liga metálica que vem apresentando um desempenho satisfatório em ambientes de maior agressividade é o aço inoxidável super duplex (AISD). Os AISD possuem boas propriedades de resistência mecânica, resistência à corrosão e tenacidade ao impacto. Essas características são derivadas da sua microestrutura bifásica composta por ferrita $(\delta)$ e austenita ( $\mathrm{\gamma}$ ) em proporções equivalentes, ou seja, $50 \%$ de cada uma aproximadamente [4-6].

Os AISD são diferenciados dos aços inoxidáveis duplex (AID) pela sua maior resistência à corrosão por pites. A utilização dos AISD ocorre em locais de elevada agressividade devido ao cloreto. Adicionalmente, os AISD também têm sido bastante utilizados nos setores energético e naval, tendo uma ampla aplicação em reatores, trocadores de calor, tubulações, bombas e vasos de pressão [4,6].

Mesmo apresentando desempenho satisfatório em diversas aplicações, os AISD podem apresentar problemas de corrosão quando sofrem algum tratamento térmico. Um desses problemas é a precipitação na faixa de temperatura entre $300^{\circ} \mathrm{C}$ e $550^{\circ} \mathrm{C}$ que corresponde principalmente a decomposição espinoidal da ferrita formando uma fase chamada de alfa linha ( $\left.\alpha^{\prime}\right)$. A fase $\alpha^{\prime}$ é uma fase deletéria que pode ocasionar um aumento do limite de resistência, um progressivo endurecimento e uma diminuição da resistência à corrosão e tenacidade do material $[4,6]$.

Este trabalho avaliará a resistência à corrosão de aços inoxidáveis super duplex de grau $5 \mathrm{~A}$ e $6 \mathrm{~A}$, segundo a norma ASTM A890/A 890M, que trata da especificação padrão para aços inoxidáveis duplex fundidos. Esses aços inoxidáveis são fundidos $e$ foram cedidos pela empresa Sulzer. São utilizados na parte estrutural de plataformas offshore e constituem os componentes fundidos como bombas de injeção, bombas boosters e bombas de incêndio [7].

A diferença entre os aços de grau $5 \mathrm{~A}$ e $6 \mathrm{~A}$ ocorre na presença de cobre e tungstênio na composição química do aço com grau $6 \mathrm{~A}$, enquanto o aço com grau $5 \mathrm{~A}$ não possui esses elementos. Devido essa diferença, será investigada a relação entre a presença dos elementos cobre e tungstênio e a precipitação da fase $\alpha$ '.

\section{MATERIAIS E MÉTODOS}

\subsection{Materiais}

Foram investigados dois aços inoxidáveis super duplex: ASTM A 890/A 890M Grau 5A e ASTM A890/A 890M Grau 6A, onde a principal diferença entre eles é a presença de cobre $(\mathrm{Cu})$ e tungstênio $(\mathrm{W})$ no aço $6 \mathrm{~A}$.

A composição química desses aços é apresentada na tabela 1.

* Contribuição técnica ao 69 Congresso Anual da ABM - Internacional e ao 14ํㅡㄹ ENEMET - Encontro Nacional de Estudantes de Engenharia Metalúrgica, de Materiais e de Minas,21 a 25 de julho de 2014, São Paulo, SP, Brasil. 


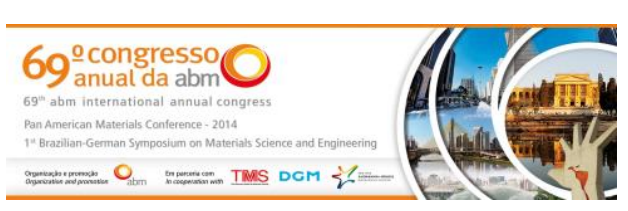

Tabela 1. Composição química dos AISD ASTM A890/A 890M GRAU 5A e 6A (em \%)

\begin{tabular}{llllllllllllll}
\hline & $\mathrm{C}$ & $\mathrm{Cr}$ & $\mathrm{Ni}$ & $\mathrm{Mn}$ & $\mathrm{Si}$ & $\mathrm{Mo}$ & $\mathrm{S}$ & $\mathrm{P}$ & $\mathrm{Cu}$ & $\mathrm{W}$ & $\mathrm{N}$ & $\mathrm{Fe}$ & Total \\
\hline 5 & 0,02 & 24,37 & 7,97 & 0,96 & 0,74 & 4,32 & 0,00 & 0,02 & 0,11 & 0,04 & 0,24 & 61,18 & 100,00 \\
$\mathrm{~A}$ & 8 & 0 & 0 & 0 & 0 & 0 & 6 & 6 & 0 & 0 & 9 & 1 & 0 \\
6 & 0,02 & 25,03 & 7,69 & 0,72 & 0,88 & 3,35 & 0,00 & 0,01 & 0,71 & 0,82 & 0,21 & 60,53 & 100,00 \\
$\mathrm{~A}$ & 9 & 0 & 0 & 0 & 0 & 0 & 6 & 8 & 0 & 0 & 1 & 6 & 0 \\
\hline
\end{tabular}

Fonte: Empresa Sulzer.

Observa-se que os teores de $\mathrm{Cu}$ e $\mathrm{W}$ deveriam ser zero para o aço inoxidável super duplex ASTM A 890/A 890M Grau 5A. Entretanto, do ponto de vista metalúrgico, $0,11 \%$ de $\mathrm{Cu}$ não é suficiente para formar o intermetálico entre $\mathrm{Ni}$ e $\mathrm{Cu}$. Então, nessa concentração, ele fica em solução sólida e contribui com a estabilização da austenita, por ser um elemento austenitizante. O tungstênio, com teor de $0,04 \%$ é considerado um elemento residual.

\subsection{Métodos}

\subsubsection{Preparação das amostras}

Os aços inoxidáveis super duplex ASTM A 890/A 890M Grau5A e 6A foram solubilizados a $1140^{\circ} \mathrm{C}$ durante 4 horas e resfriados em água. O tratamento visou dissolver todas as fases secundárias formadas durante 0 resfriamento de solidificação. O resfriamento em água foi realizado para evitar que as fases oriundas do processo de solidificação voltassem a precipitar. Essa solubilização foi realizada pela empresa Sulzer, a qual cedeu o material para o estudo.

As amostras, já solubilizadas, foram recebidas na forma de tarugo e, em seguida, foram cortadas com disco abrasivo, refrigerado com emulsão, utilizando uma cortadeira do tipo cut-off, em dois tamanhos: $1 \mathrm{~cm} \times 1 \mathrm{~cm} \times 1 \mathrm{~cm} \mathrm{e} 1 \mathrm{~cm} \times 1 \mathrm{~cm} \times 2,5$ $\mathrm{cm}$, sendo esse último tamanho para a realização do ensaio de dureza Brinell e o primeiro tamanho para o restante dos ensaios, como mostra a figura abaixo.

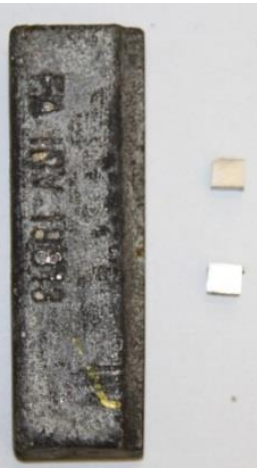

Figura 1. Amostra como recebida e depois do corte.

Após o corte, as peças foram submetidas a um tratamento térmico, em um forno tipo FDG 3P-S, para caracterização de fases deletérias, mais especificamente para 0 estudo da fase $\alpha$, que precipita a uma temperatura aproximada de $475^{\circ} \mathrm{C}$ para aços inoxidáveis super duplex. Foi variado o tempo do tratamento térmico para verificar a influência do tempo em que o material fica exposto a essa temperatura. Os seguintes tratamentos térmicos foram realizados:

2 horas a $475^{\circ} \mathrm{C}$ e resfriamento em água;

10 horas a $475^{\circ} \mathrm{C}$ e resfriamento em água;

\footnotetext{
* Contribuição técnica ao 69ำ Congresso Anual da ABM - Internacional e ao 14ํㅡㄹ ENEMET - Encontro Nacional de Estudantes de Engenharia Metalúrgica, de Materiais e de Minas,21 a 25 de julho de 2014, São Paulo, SP, Brasil.
} 


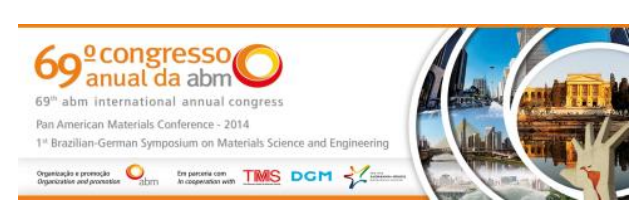

\section{$\checkmark \quad 50$ horas a $475^{\circ} \mathrm{C}$ e resfriamento em água; \\ $\checkmark \quad 100$ horas a $475^{\circ} \mathrm{C}$ e resfriamento em água.}

Após o tratamento térmico para caracterização da fase deletéria $\alpha$ ', foram embutidas três amostras para cada tempo de tratamento e também três amostras do branco, que é o material como foi recebido, para ambos os aços inoxidáveis super duplex ASTM A 890/A 890M Grau 5A e Grau 6A. Para embutir, foi utilizada resina e um fio de cobre para que pudesse passar corrente durante os ensaios de corrosão. A amostra embutida é mostrada na figura abaixo.

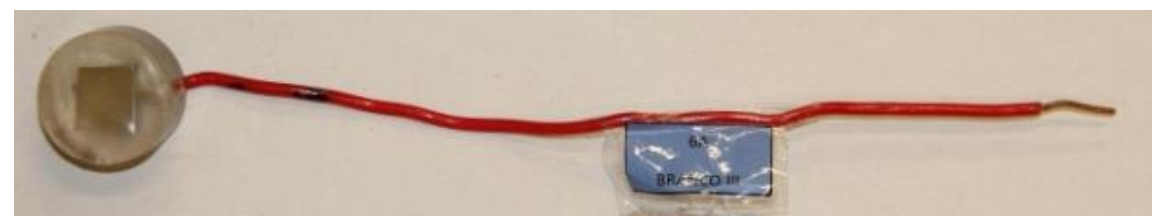

Figura 2. Amostra embutida.

Para a caracterização microestrutural e ensaios de corrosão, foram utilizadas as amostras embutidas em resina. Já para o ensaio de dureza Brinell, foram utilizadas as peças da forma como saíram do forno, com o tamanho de $1 \mathrm{~cm} \times 1 \mathrm{~cm} \times 2,5 \mathrm{~cm}$, sem serem embutidas.

\subsubsection{Caracterização microestrutural}

Primeiramente as amostras foram lixadas em uma politriz utilizando lixas com as seguintes granulometrias: $100-220-400-600-1200-1500-2500$ mesh. Após serem lixadas, as peças foram polidas com pasta diamantada com granulometria de $1 \mu \mathrm{m}$.

Após polimento, foi realizado o ataque químico nas amostras para a detecção das fases presentes com a utilização do reagente Behara, que foi preparado em duas etapas. Na primeira etapa foi feita uma solução estoque com a seguinte composição: $1000 \mathrm{~mL}$ de água destilada $+200 \mathrm{~mL}$ de $\mathrm{HCl}[4,8]$. Na segunda etapa foi adicionado a $100 \mathrm{~mL}$ de solução estoque cerca de 1,0 a 1,5 g de metabissulfito de potássio.

As amostras foram imersas nessa solução em temperatura ambiente e permaneceram cerca de 20 a 30 s. Após esse tempo de imersão, as amostras foram lavadas com água destilada em abundância, seguida de álcool e secadas com a utilização de um secador com jato de ar quente.

Para que a morfologia das microestruturas fosse analisada, foi utilizado um microscópio óptico da marca Leica, modelo DMI 3000 M, acoplado à câmera de vídeo e placa digitalizadora acoplada a um computador.

\subsubsection{Quantificação de fases}

Após registro fotográfico das microestruturas das amostras, foi feita a quantificação das fases presentes, austenita e ferrita, para que se pudesse saber a quantidade de cada uma delas. Foram utilizadas 5 fotos para cada amostra e, no final, foi feita uma média.

A quantificação foi feita utilizando o software LAS V4.2, o qual utiliza a diferença de cor das fases para apresentar a quantidade de cada uma, como pode ser observado na figura 3.

\footnotetext{
* Contribuição técnica ao $69^{\circ}$ Congresso Anual da ABM - Internacional e ao 14ํㅡㄹ ENEMET - Encontro Nacional de Estudantes de Engenharia Metalúrgica, de Materiais e de Minas,21 a 25 de julho de 2014, São Paulo, SP, Brasil.
} 

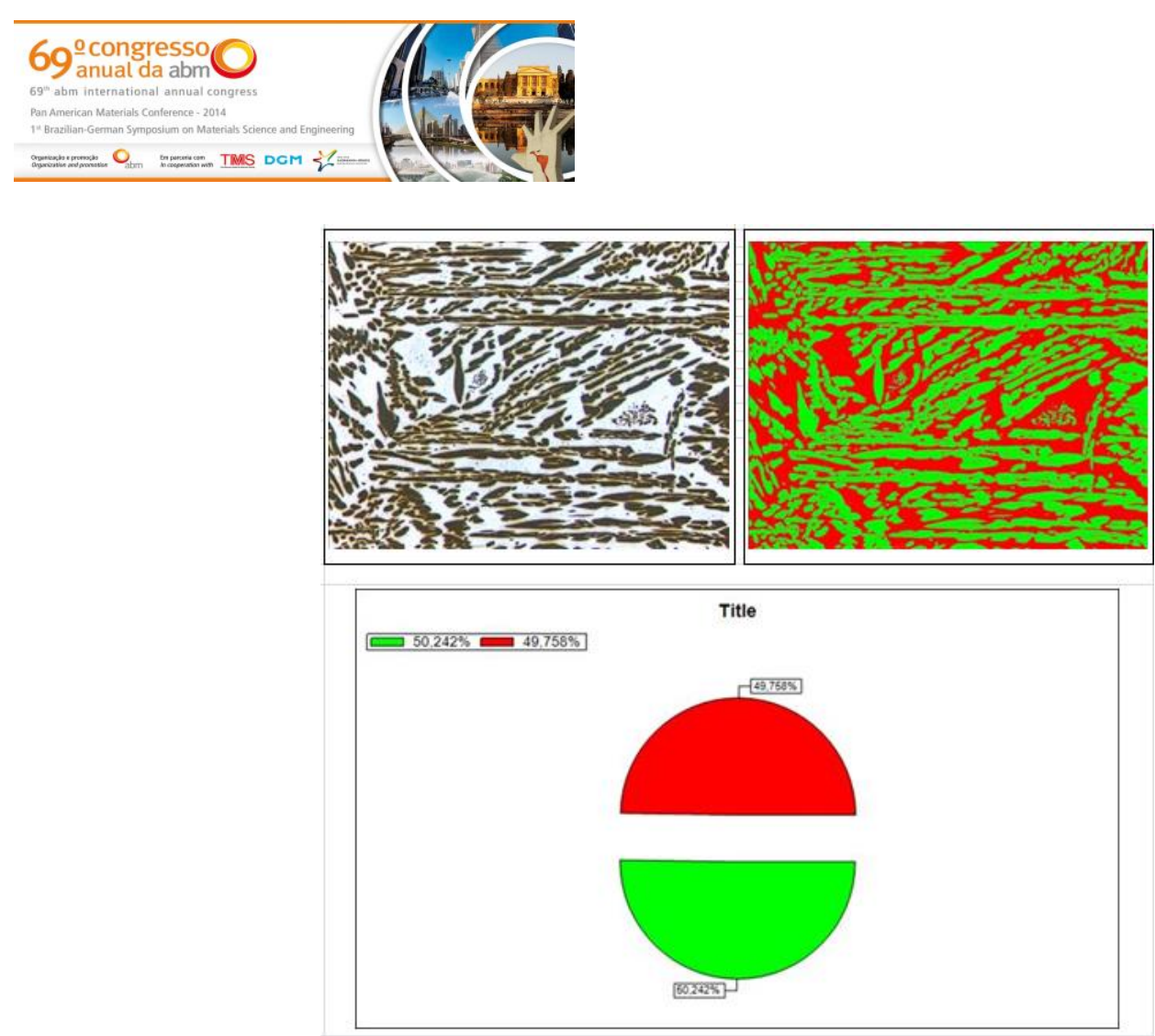

Figura 3. Exemplo de quantificação de fases utilizando o software LAS V4.2.

\subsubsection{Ensaios mecânicos}

\subsubsection{Dureza Brinell}

O ensaio de dureza Brinell foi realizado no Laboratório de ensaios mecânicos da Universidade Federal do Ceará.

Para a realização do ensaio, as amostras foram lixadas até 200 mesh e foi utilizada a norma da ABNT NM ISO 6506-1 [9]. Foram realizadas 5 medições de cada amostra com uma força de $187,5 \mathrm{kgf}$, com uma esfera de diâmetro de $2,5 \mathrm{~mm}$ e com um tempo de $15 \mathrm{~s}$.

Depois de realizado o ensaio, o valor da dureza Brinell foi calculado de acordo com a seguinte equação:

$$
H B=\frac{2 \cdot F}{\pi \cdot D \cdot\left(D-\sqrt{D^{2}-d m^{2}}\right.}
$$

onde:

$\mathrm{HB}=$ dureza Brinell;

$\mathrm{F}=$ força de ensaio;

$\mathrm{D}=$ diâmetro da esfera;

$\mathrm{dm}=$ diâmetro médio da impressão.

\subsubsection{Ensaios eletroquímicos}

Os ensaios eletroquímicos foram realizados utilizando uma célula clássica de três eletrodos. O eletrodo de trabalho utilizado foi a amostra em análise, o contra eletrodo foi de platina e o eletrodo de referência de $\mathrm{Ag} / \mathrm{AgCl}$. Para a realização das medidas foi utilizado um potenciostato / galvanostato modelo PGSTAT302N. Antes da realização de cada ensaio eletroquímico as amostras foram lixadas em uma politriz utilizando lixas com as seguintes granulometrias: $100-220-400-600-1200$. Em seguida, a interface entre a resina e o eletrodo de trabalho foi protegido com esmalte para que a corrosão por frestas fosse evitada. A solução utilizada foi de $\mathrm{NaCl} 40000$ ppm. Já para o ensaio de temperatura crítica de pite foi seguida a norma ASTM G

\footnotetext{
* Contribuição técnica ao 69ำ Congresso Anual da ABM - Internacional e ao 14ํㅡㄹ ENEMET - Encontro Nacional de Estudantes de Engenharia Metalúrgica, de Materiais e de Minas,21 a 25 de julho de 2014, São Paulo, SP, Brasil.
} 


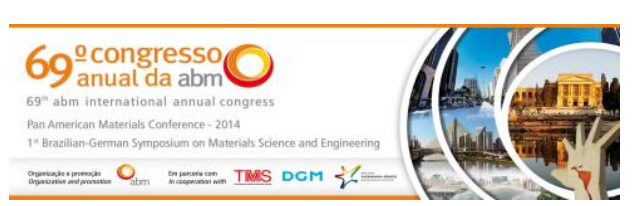

150-13, por isso as amostras foram lixadas até 600 mesh e a solução utilizada foi $\mathrm{NaCl}$ $1 \mathrm{M}$ [10]. Antes do início dos ensaios eletroquímicos, as amostras foram imersas durante 1 hora na solução de trabalho para estabilização do potencial. Todos os ensaios foram realizados em triplicata.

\subsubsection{Polarização potenciodinâmica}

Para a polarização potenciodinâmica anódica, a velocidade de varredura do ensaio foi de $1 \mathrm{mV} / \mathrm{s}$, o potencial inicial foi o de circuito aberto, o potencial final foi de $1,4 \mathrm{~V}$ e foi encerrada manualmente quando a corrente atingiu um valor aproximado de $0,001 \mathrm{~A}$.

Após o final do ensaio, foram registradas fotografias para avaliar a superfície do material com a utilização de um microscópio óptico da marca Leica, modelo DMI 3000 $\mathrm{M}$, acoplado à câmera de vídeo e placa digitalizadora acoplada a um computador.

\subsubsection{Espectroscopia de impedância eletroquímica}

As medições de impedância ocorreram na faixa de frequência de $40 \mathrm{kHz}-2,5 \mathrm{mHz}$. Foi utilizada uma onda senoidal com amplitude de $15 \mathrm{mV}$ sobre o potencial de circuito aberto, totalizando 49 pontos medidos.

\subsubsection{Temperatura crítica de pite}

Os ensaios de temperatura crítica de pite foram realizados de acordo com a norma ASTM G150 - 13. A preparação dos corpos de provas e a solução estão descritas no item 2.2.4.

A temperatura crítica de pite consiste em um experimento cronoamperométrico, onde foi utilizado um potenciostato/galvanostato modelo Metrohm PT1000 conectado ao módulo PX1000. Como pode ser observado na figura abaixo, a célula é encamisada para que haja o controle da temperatura.

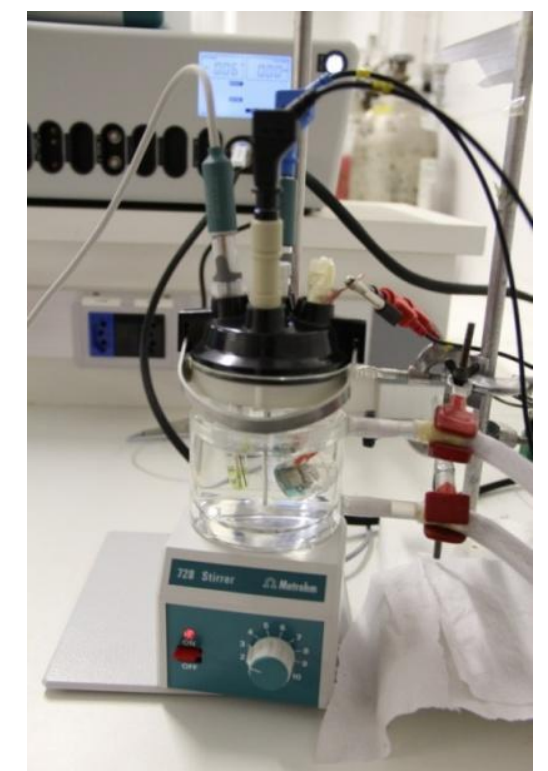

Figura 4. Célula eletroquímica utilizada para o ensaio de temperatura crítica de pite.

Utilizando um banho termostático, a temperatura foi controlada manualmente com uma taxa de aquecimento de $1{ }^{\circ} \mathrm{C}$ por minuto a partir de $22^{\circ} \mathrm{C}$ até que houvesse um aumento brusco da corrente, que significa a formação do pite [11]. Foi aplicado um potencial constante de $700 \mathrm{mV}$ na amostra em relação ao eletrodo de referência. Após

\footnotetext{
* Contribuição técnica ao 69ำ Congresso Anual da ABM - Internacional e ao 14ํㅡㄹ ENEMET - Encontro Nacional de Estudantes de Engenharia Metalúrgica, de Materiais e de Minas,21 a 25 de julho de 2014, São Paulo, SP, Brasil.
} 


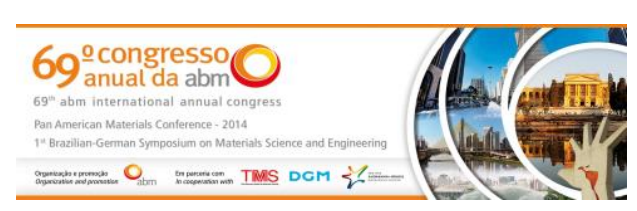

o final do ensaio, foram registradas fotografias para avaliar a superfície do material com a utilização de um microscópio óptico da marca Leica, modelo DMI 3000 M, acoplado à câmera de vídeo e placa digitalizadora acoplada a um computador.

\section{RESULTADOS E DISCUSSÃO}

\subsection{Caracterização Microestrutural}

Inicialmente foi feita a caracterização microestrutural dos aços inoxidáveis $5 \mathrm{~A}$ e $6 \mathrm{~A}$ para que pudesse ser verificada e comprovada a estrutura bifásica dos aços super duplex, que é composta por uma matriz ferrita e ilhas de austenita.

Como pode ser verificado nas figuras 5 e 6 , as microestruturas dos aços $5 \mathrm{~A}$ e $6 \mathrm{~A}$, para todos os tempos de tratamento térmico a $475^{\circ} \mathrm{C}(2,10,50$ e 100 horas) e para a amostra como foi recebida (branco), estão coerentes. Todas elas apresentaram uma microestrutura bifásica composta por uma matriz ferrítica $(\delta)$ e ilhas de austenita $(Y)$ em proporções aparentemente equivalentes.

$\mathrm{O}$ ataque com o reagente Behara e o uso do microscópio óptico não permitem a visualização da fase alfa linha ( $\alpha$ '), pois esta é muito pequena, da ordem de 20 a 200 $\AA$, e possui pouco contraste e similaridade estrutural com a matriz ferrítica $[12,13]$.

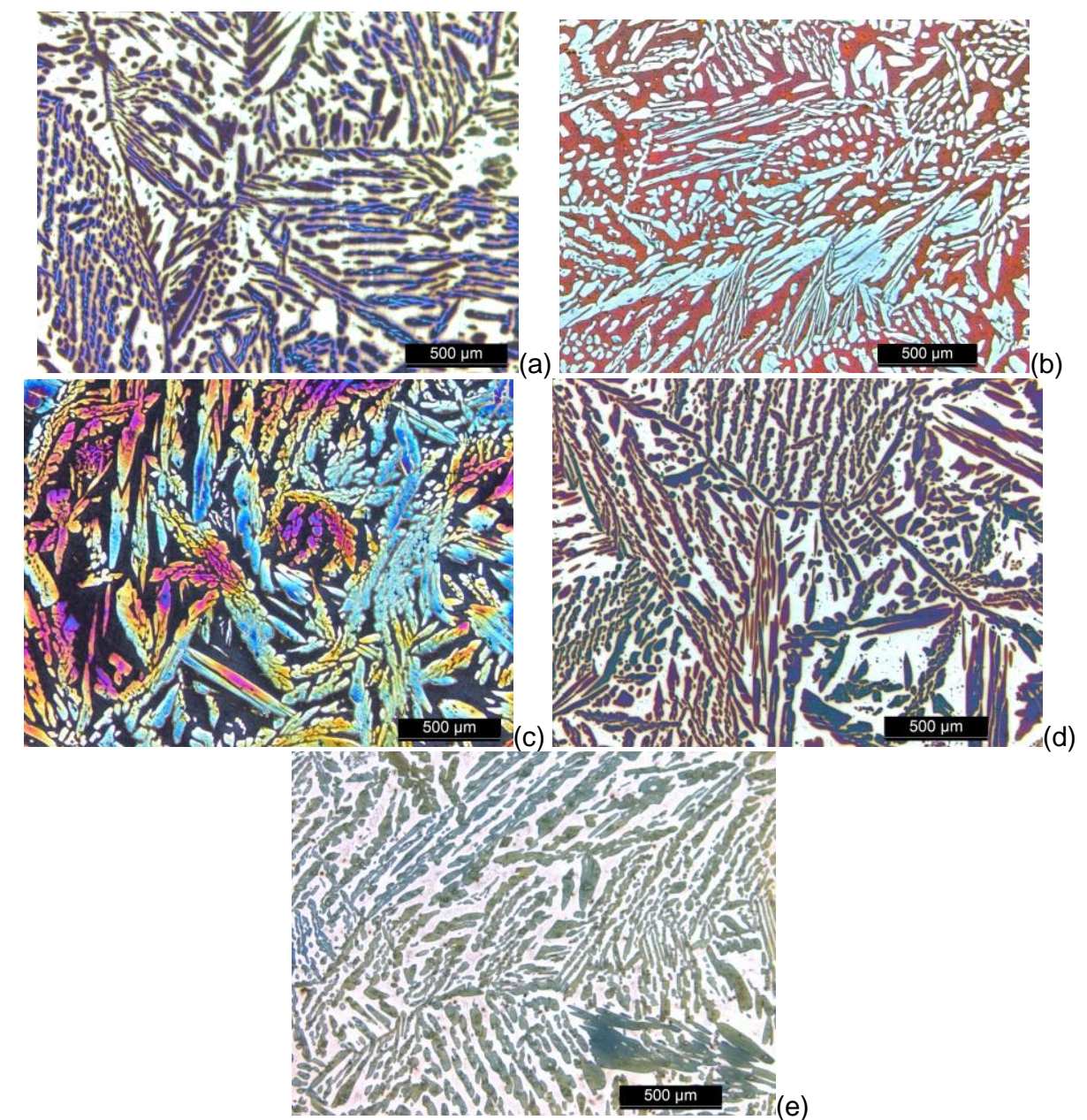

Figura 5. Microestruturas do aço inoxidável super duplex 5A como recebido (a), tratado termicamente a $475{ }^{\circ} \mathrm{C}$ por $2 \mathrm{~h}(\mathrm{~b})$, por $10 \mathrm{~h}$ (c), por $50 \mathrm{~h}(\mathrm{~d})$ e por $100 \mathrm{~h}(\mathrm{e})$ (aumento de $50 \mathrm{x}$ ).

\footnotetext{
* Contribuição técnica ao $69^{\circ}$ Congresso Anual da ABM - Internacional e ao 14ํㅡㄹ ENEMET - Encontro Nacional de Estudantes de Engenharia Metalúrgica, de Materiais e de Minas,21 a 25 de julho de 2014, São Paulo, SP, Brasil.
} 


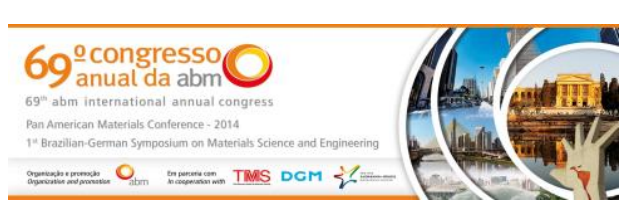

As melhores características de um aço inoxidável super duplex são obtidas quando a sua composição de austenita e ferrita são equivalentes, mas nem sempre isso é possível, pois essa composição depende da composição química e do tempo de resfriamento da liga, podendo, dessa forma, variar [14]. De acordo com [15], é geralmente aceito que as propriedades favoráveis desse tipo de aço podem ser conseguidas para um balanço de fases no intervalo de 30 a $70 \%$ de ferrita e austenita, portanto, o resultado obtido na quantificação de fases para as amostras em questão são coerentes e satisfatórios.

\subsection{Ensaios Mecânicos}

Foi realizado o ensaio mecânico de dureza Brinell para que fosse verificado o comportamento da dureza conforme o aumento do tempo de tratamento térmico a 475 ${ }^{\circ} \mathrm{C}$ para a precipitação da fase alfa linha.

\subsubsection{Dureza Brinell}

Conforme era esperado, tanto para o aço inoxidável super duplex $5 \mathrm{~A}$ quanto para o aço $6 \mathrm{~A}$, houve um significativo aumento da dureza conforme aumentou o tempo de tratamento térmico a $475^{\circ} \mathrm{C}$, que é um indicativo da precipitação da fase $\alpha^{\prime}$ [4].

Houve um aumento da dureza nas primeiras horas de tratamento térmico, que é um indicativo da forte cinética da precipitação da fase alfa linha, havendo, em seguida, uma diminuição nessa taxa de aumento da dureza. É importante observar que a diminuição na taxa de aumento da dureza foi mais significativa para o aço $6 \mathrm{~A}$ do que para o aço $5 \mathrm{~A}$, indicando uma possível influência da menor quantidade de molibdênio e da presença do cobre na composição do aço 6A [4].

Foi observada uma semelhança entre os resultados obtidos neste trabalho e os resultados obtidos por [4] para o aço UNS S32750 e os resultados obtidos por [16] para o aço UNS S31803.

Os resultados obtidos para a variação da dureza Brinell com relação ao tempo de tratamento térmico a $475^{\circ} \mathrm{C}$ podem ser observados na figura 7 apresentada abaixo.

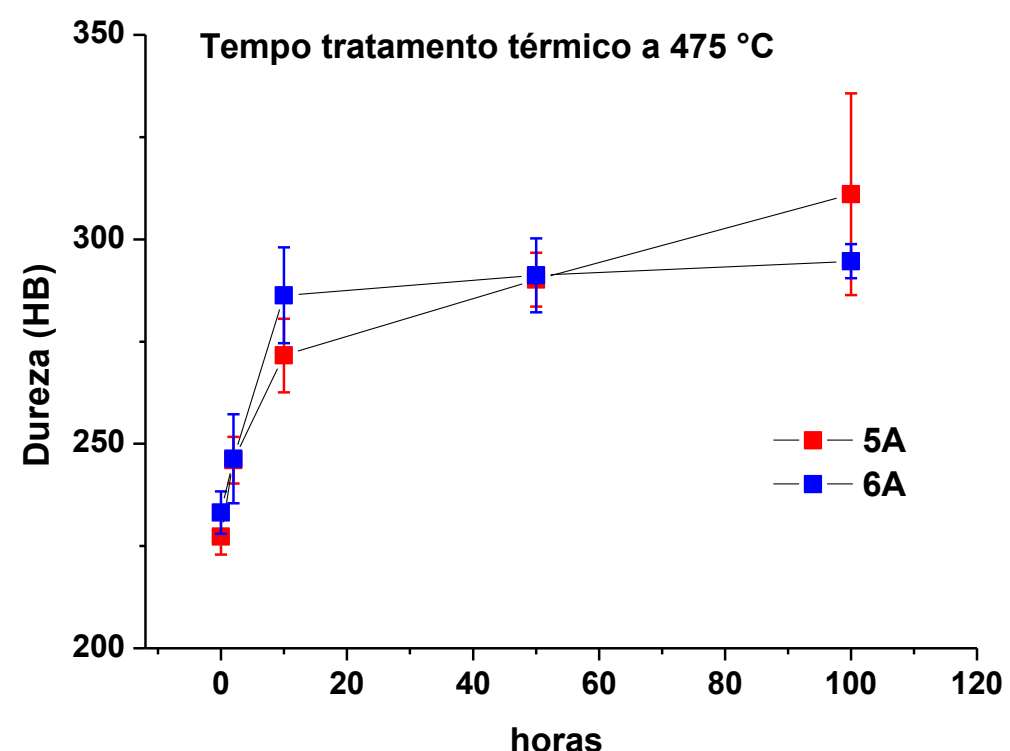

Figura 7. Variação da dureza Brinell para os aços $5 \mathrm{~A}$ e $6 \mathrm{~A}$ após diversos tempos de tratamento térmico a $475^{\circ} \mathrm{C}$

\footnotetext{
* Contribuição técnica ao $69^{\circ}$ Congresso Anual da ABM - Internacional e ao 14ํㅡㄹ ENEMET - Encontro Nacional de Estudantes de Engenharia Metalúrgica, de Materiais e de Minas,21 a 25 de julho de 2014, São Paulo, SP, Brasil.
} 


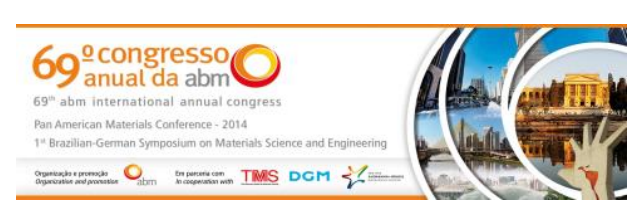

\subsection{Ensaios Eletroquímicos}

\subsubsection{Polarização potenciodinâmica anódica}

Nas figuras 8 e 10 podem ser observados os resultados da polarização anódica para todos os tempos de tratamento térmico e para o branco dos aços $5 \mathrm{~A}$ e $6 \mathrm{~A}$, respectivamente. Já as figuras 9 e 11 mostram as superfícies de todas as amostras, após os ensaios de polarização anódica, dos aços $5 \mathrm{~A}$ e $6 \mathrm{~A}$, respectivamente.

Como pode ser observado na figura 8 , todas as amostras do aço $5 \mathrm{~A}$ apresentaram valores de potenciais de corrosão semelhantes. As amostras tratadas por 10 horas, tanto para amostra 5A quanto 6A (tabelas 4 e 5) apresentaram uma menor corrente de passivação, beneficiando o início do processo de formação do filme. Adicionalmente, verifica-se que a mesma amostra apresentou o início de um pico que se iniciou por volta de um potencial de $0,3 \mathrm{~V}$. Nesse ponto, ocorre a dissolução do filme, seguida de uma repassivação, indicando que para essas amostras o filme é instável nessa faixa de potencial. Este mesmo processo de dissolução, de modo mais acentuado, foi observado para as amostras tratada a $475^{\circ} \mathrm{C}$ por 50 horas e 100 horas. Para as amostras $6 \mathrm{~A}$, como pode ser observado na figura 13 , não ocorreu a dissolução do filme em torno do potencial de $0,3 \mathrm{~V}$, indicando uma possível influência do cobre e do tungstênio na estabilidade do filme da passivação.

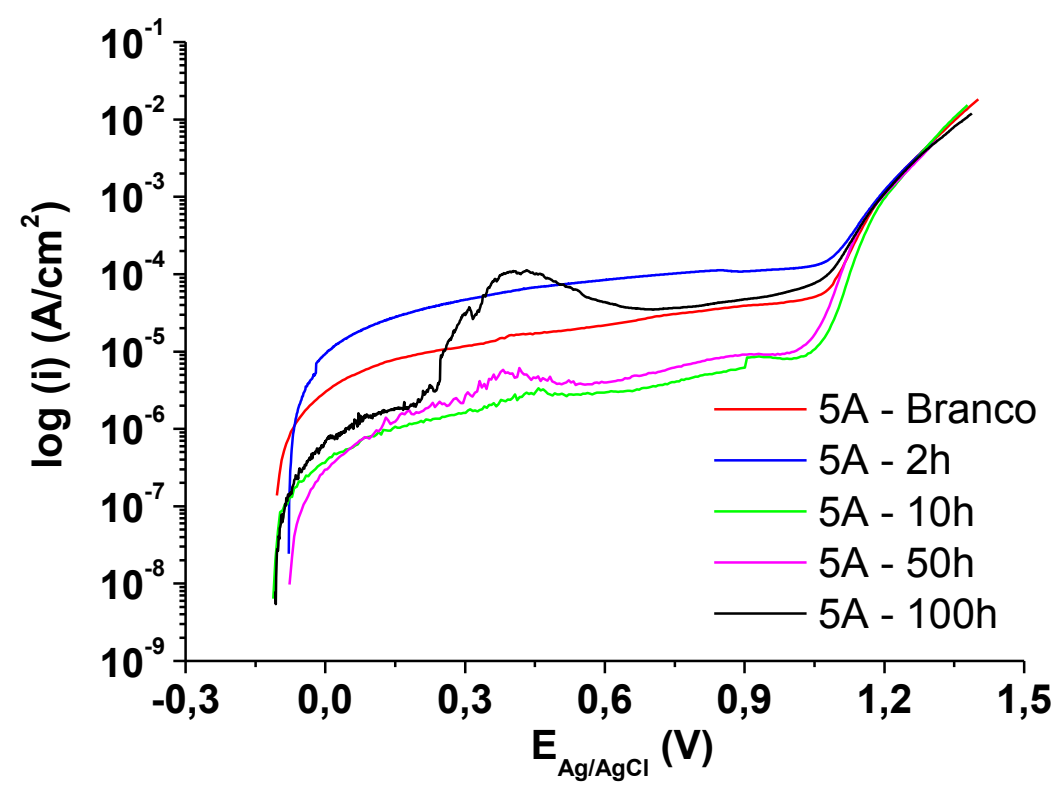

Figura 8. Curvas de polarização potenciodinâmica anódica para o aço $5 \mathrm{~A}$ com diferentes tempos de tratamento térmico a $475^{\circ} \mathrm{C}$.

Abaixo seguem as fotos das superfícies das amostras do aço $5 \mathrm{~A}$ após o ensaio de polarização anódica.

\footnotetext{
* Contribuição técnica ao 69ำ Congresso Anual da ABM - Internacional e ao 14ํㅡㄹ ENEMET - Encontro Nacional de Estudantes de Engenharia Metalúrgica, de Materiais e de Minas,21 a 25 de julho de 2014, São Paulo, SP, Brasil.
} 
(a)

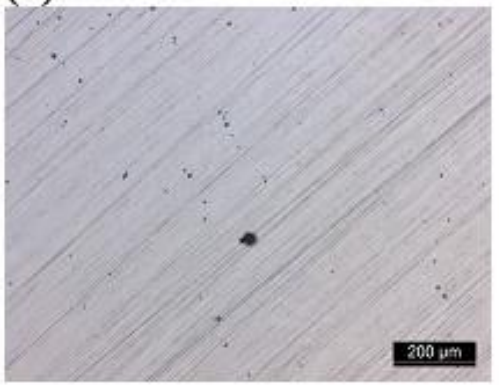

(b)

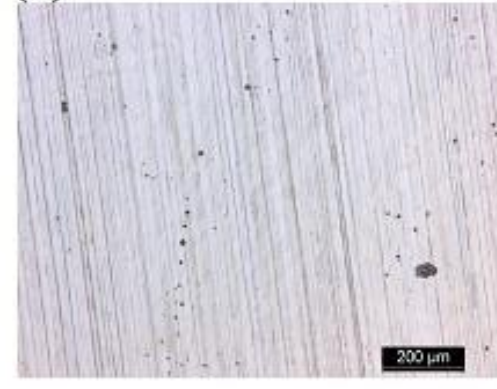

(c)

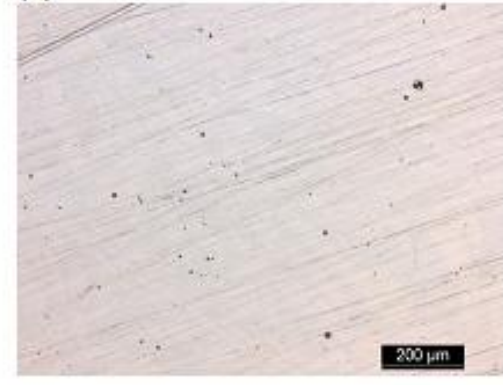

(d)

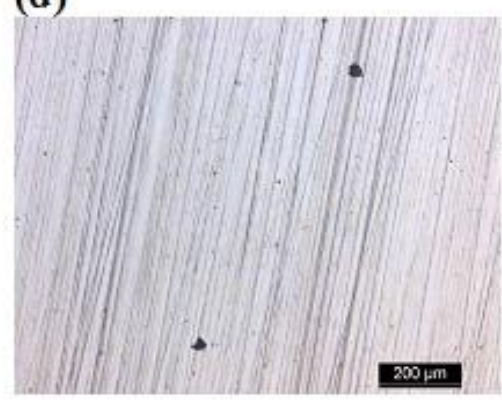

(e)

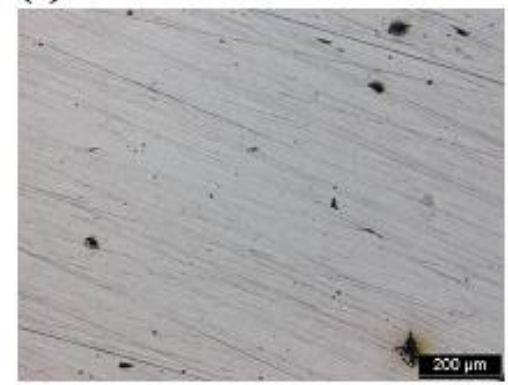

Figura 9. Fotos após o ensaio de polarização potenciodinâmicaanódica para o aço $5 \mathrm{~A}$ como recebido (a), tratado termicamente a $475^{\circ} \mathrm{C}$ por $2 \mathrm{~h}$ (b), por $10 \mathrm{~h}$ (c), por $50 \mathrm{~h}$ (d) e por $100 \mathrm{~h} \mathrm{(e)} \mathrm{(aumento} \mathrm{de}$ 100x).

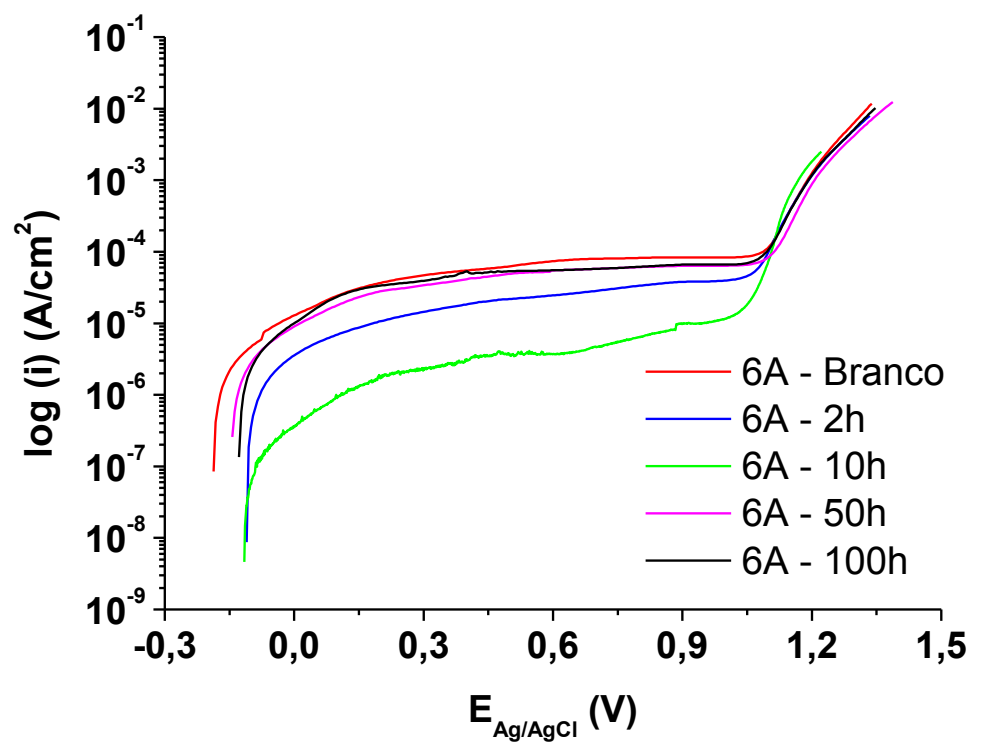

Figura 10. Curvas de polarização potenciodinâmica anódica para o aço $6 \mathrm{~A}$ com diferentes tempos de tratamento térmico a $475^{\circ} \mathrm{C}$.

Abaixo seguem as fotos das superfícies das amostras do aço 6A após o ensaio de polarização anódica.

\footnotetext{
* Contribuição técnica ao 69ํ Congresso Anual da ABM - Internacional e ao 14ํㅡㄹ ENEMET - Encontro Nacional de Estudantes de Engenharia Metalúrgica, de Materiais e de Minas,21 a 25 de julho de 2014, São Paulo, SP, Brasil.
} 
(a)

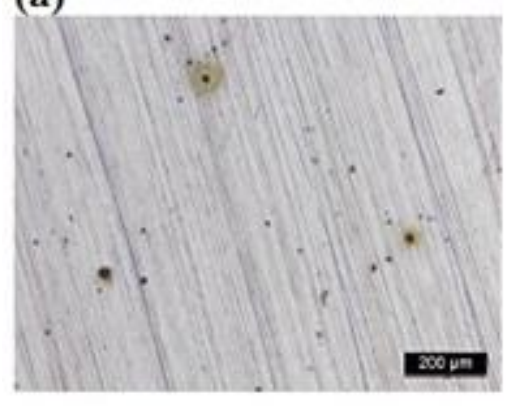

(d)

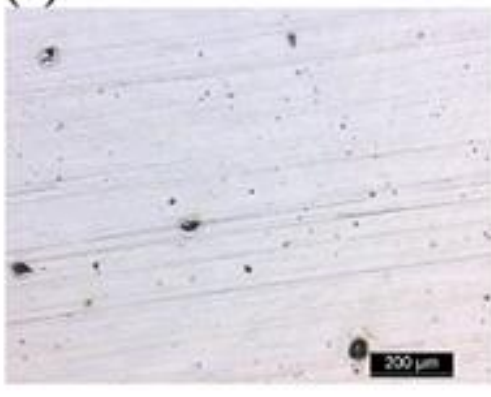

(b)

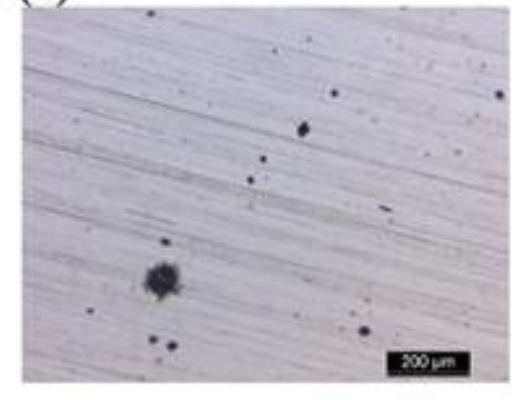

(e) (c)

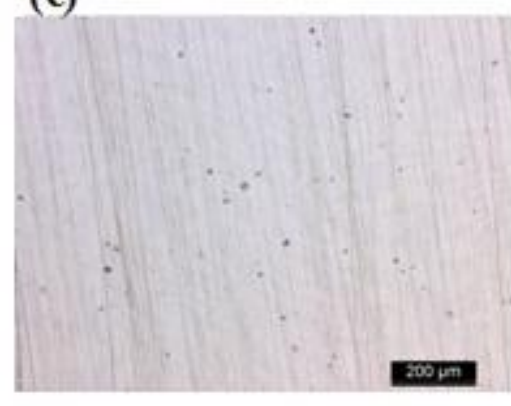

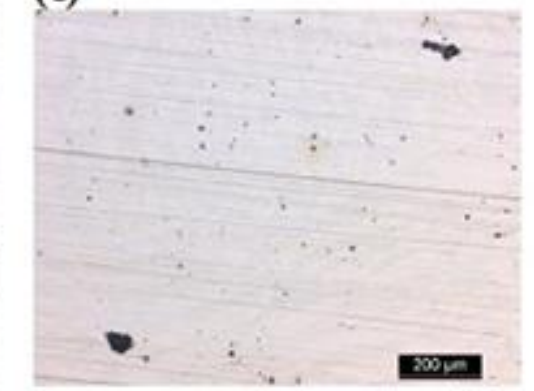

Figura 11. Fotos após o ensaio de polarização potenciodinâmica anódica para o aço $6 \mathrm{~A}$ como recebido (a), tratado termicamente a $475^{\circ} \mathrm{C}$ por $2 \mathrm{~h}$ (b), por $10 \mathrm{~h}$ (c), por $50 \mathrm{~h}$ (d) e por $100 \mathrm{~h} \mathrm{(e)} \mathrm{(aumento} \mathrm{de}$ 100x).

Nas tabelas abaixo podem ser visualizados os valores das correntes de passivação $\left(i_{p}\right)$ e dos potenciais de quebra da passivação $\left(E_{p}\right)$ para os aços $5 \mathrm{~A}$ e $6 \mathrm{~A}$.

Tabela 4. Correntes de passivação (ip) e potenciais de quebra da passivação (Ep) para o aço 5A

\begin{tabular}{llllll}
\hline & Branco & $2 \mathrm{~h}$ & $10 \mathrm{~h}$ & $50 \mathrm{~h}$ & $100 \mathrm{~h}$ \\
\hline $\mathrm{i}_{p}$ & 3,39 & 11,6 & 0,57 & 0,78 & 44,8 \\
$\mathrm{E}_{\mathrm{p}}$ & 1,08 & 1,08 & 1,04 & 1,03 & 1,07 \\
\hline
\end{tabular}

Tabela 5. Correntes de passivação (ip) e potenciais de quebra da passivação (Ep) para o aço $6 \mathrm{~A}$

\begin{tabular}{cccccc}
\hline & Branco & $2 \mathrm{~h}$ & $10 \mathrm{~h}$ & $50 \mathrm{~h}$ & $100 \mathrm{~h}$ \\
\hline $\mathrm{i}_{\mathrm{p}}\left(\mu \mathrm{A} / \mathrm{cm}^{2}\right)$ & 14,1 & 4,07 & 0,70 & 15,0 & 14,3 \\
$\mathrm{E}_{\mathrm{p}}(\mathrm{V})$ & 1,09 & 1,06 & 1,02 & 1,11 & 1,08 \\
\hline
\end{tabular}

\subsubsection{Espectroscopia de impedância eletroquímica}

Nas figuras 12 e 13 são apresentados os diagramas de Bode para o ensaio de espectroscopia de impedância eletroquímica para os aços $5 \mathrm{~A}$ e $6 \mathrm{~A}$, respectivamente. Como pode ser observado na figura 12, apresentada abaixo, para o aço $5 \mathrm{~A}$, não houve uma influência significativa no tempo de tratamento térmico com relação a resistência à corrosão, sendo todas as curvas bastante similares.

\footnotetext{
* Contribuição técnica ao 69ำ Congresso Anual da ABM - Internacional e ao 14ํㅡㄹ ENEMET - Encontro Nacional de Estudantes de Engenharia Metalúrgica, de Materiais e de Minas,21 a 25 de julho de 2014, São Paulo, SP, Brasil.
} 


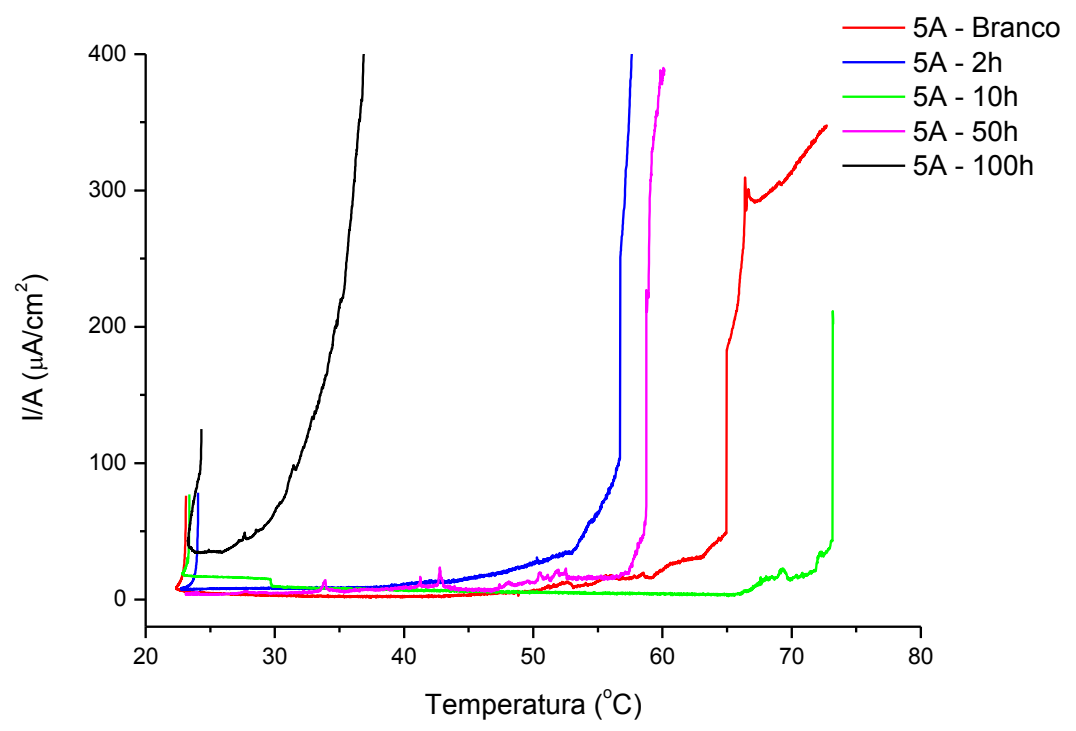

Figura 14. Curvas de CPT para o aço $5 \mathrm{~A}$ com diferentes tempos de tratamento térmico a $475^{\circ} \mathrm{C}$.

Abaixo seguem as fotos das superfícies das amostras do aço $5 \mathrm{~A}$ após o ensaio de temperatura crítica de pite.

(a)

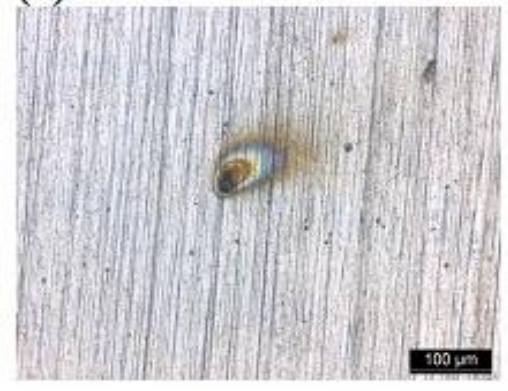

(d)

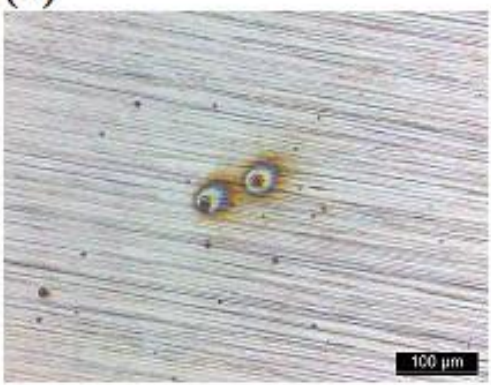

(b)

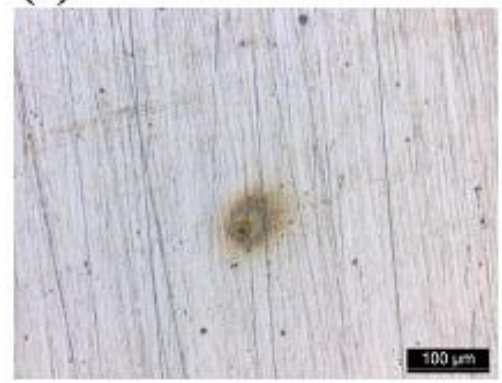

(c)

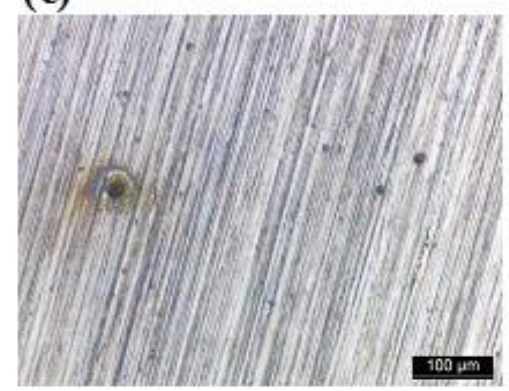

(e)

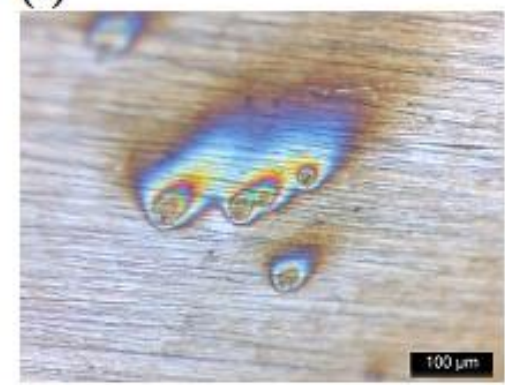

Figura 15. Fotos após o ensaio de temperatura crítica de pite para o aço 5A como recebido (a), tratado termicamente a $475^{\circ} \mathrm{C}$ por $2 \mathrm{~h}$ (b), por $10 \mathrm{~h}$ (c), por $50 \mathrm{~h}$ (d) e por $100 \mathrm{~h}$ (e) (aumento de 200x).

\footnotetext{
* Contribuição técnica ao 69ํ Congresso Anual da ABM - Internacional e ao 14ํㅡㄹ ENEMET - Encontro Nacional de Estudantes de Engenharia Metalúrgica, de Materiais e de Minas,21 a 25 de julho de 2014, São Paulo, SP, Brasil.
} 


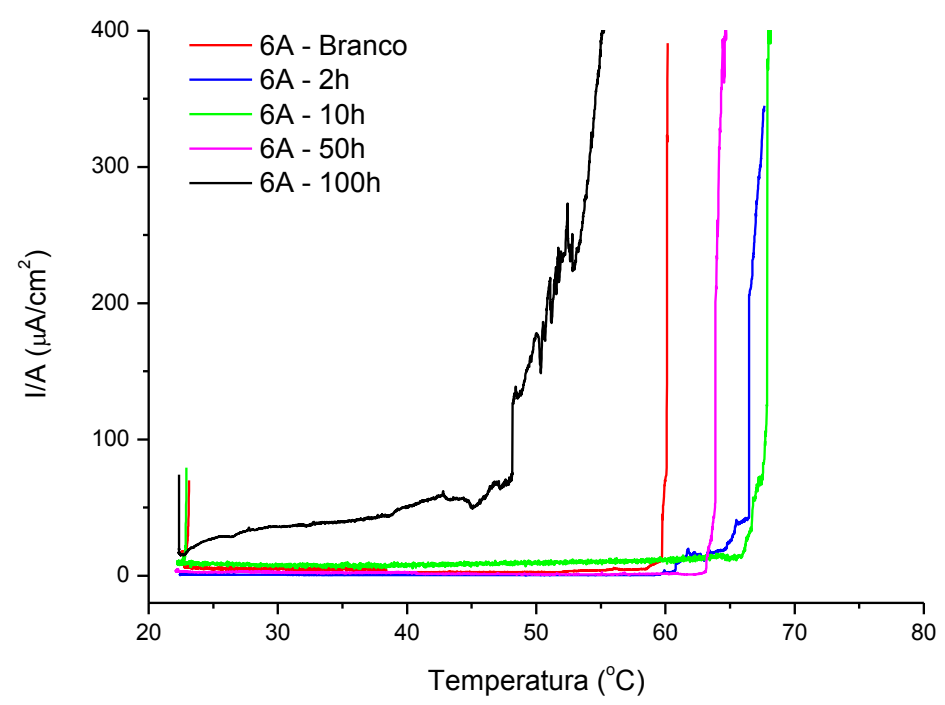

Figura 16. Curvas de CPT para o aço $5 \mathrm{~A}$ com diferentes tempos de tratamento térmico a $475^{\circ} \mathrm{C}$.

Abaixo seguem as fotos das superfícies das amostras do aço $6 \mathrm{~A}$ após o ensaio de temperatura crítica de pite.

(a)

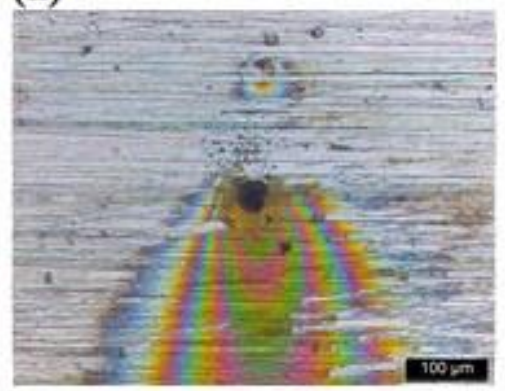

(d)

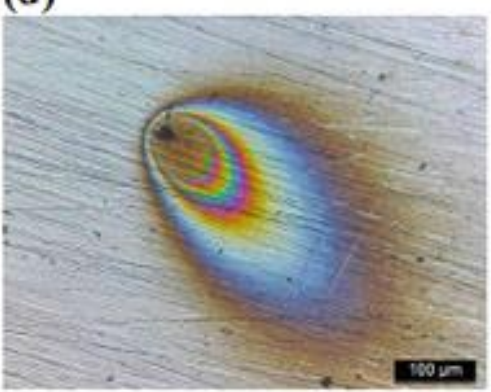

(b)

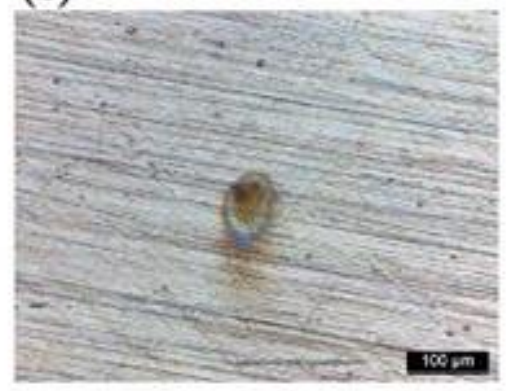

(c)

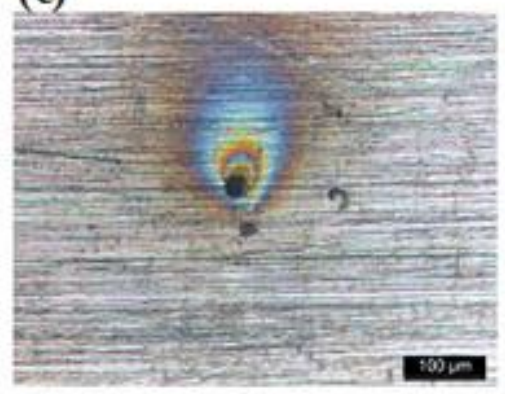

(e)

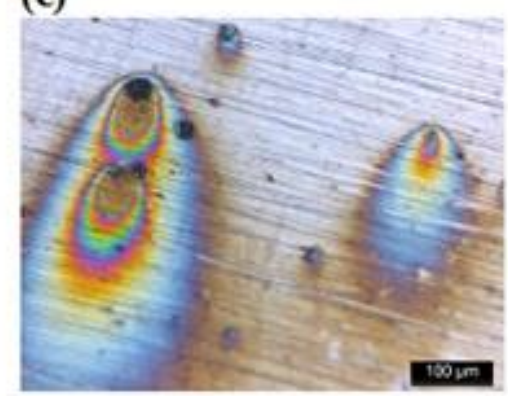

Figura 17. Fotos após o ensaio de temperatura crítica de pite para o aço $6 \mathrm{~A}$ como recebido (a), tratado termicamente a $475{ }^{\circ} \mathrm{C}$ por $2 \mathrm{~h}(\mathrm{~b})$, por $10 \mathrm{~h}$ (c), por $50 \mathrm{~h}$ (d) e por $100 \mathrm{~h}$ (e) (aumento de 200x).

Os valores das temperaturas críticas de pite, para cada tempo de tratamento térmico e para o branco, para os dois aços estudados podem ser visualizados na tabela 5 apresentada abaixo.

\footnotetext{
* Contribuição técnica ao 69ํ Congresso Anual da ABM - Internacional e ao 14ํㅡㄹ ENEMET - Encontro Nacional de Estudantes de Engenharia Metalúrgica, de Materiais e de Minas,21 a 25 de julho de 2014, São Paulo, SP, Brasil.
} 
Tabela 5. CPTpara os aços 5A e 6A

\begin{tabular}{crc}
\hline Amostra & $5 \mathrm{~A}\left({ }^{\circ} \mathrm{C}\right)$ & $6 \mathrm{~A}\left({ }^{\circ} \mathrm{C}\right)$ \\
\hline Branco & 65,0 & 60,12 \\
$2 \mathrm{~h}$ & 56,6 & 66,4 \\
$10 \mathrm{~h}$ & 73,1 & 67,8 \\
$50 \mathrm{~h}$ & 58,8 & 63,9 \\
$100 \mathrm{~h}$ & 31,8 & 48,1 \\
\hline
\end{tabular}

\section{CONCLUSÃO}

1. A dureza do material investigado aumentou com o aumento do tempo de tratamento térmico, que é um indicativo para a precipitação da fase $\alpha$;

2. A maior taxa de formação da fase a' para o aço $5 \mathrm{~A}$ deve-se, provavelmente, a maior quantidade do molibdênio na composição do aço, que contribui na cinética de formação desta fase;

3. As amostras, para ambos os aços $5 \mathrm{~A}$ e $6 \mathrm{~A}$, tratadas a $475{ }^{\circ} \mathrm{C}$ por 10 horas apresentaram a menor densidade de corrente de passivação, indicando um efeito benéfico do tratamento térmico por 10 horas na cinética de formação do filme de passivação;

4. A presença do cobre e do tungstênio na composição química do aço $6 \mathrm{~A}$ ajudou na estabilização do filme passivo.

5. O ensaio para determinação da temperatura crítica de pite foi coerente aos ensaios eletroquímicos, indicando maior estabilidade para o filme passivo para a amostra tratada por 10 horas

\section{Agradecimentos}

Os autores agradecem a CAPES, FUNCAP, Petrobrás e ao CNPq pelo apoio financeiro e a SULZER por ter cedido os aços investigados.

\section{REFERÊNCIAS}

1 Souza ED. Análise de corrosão por meio de perda de massa e espessura em aços pela ação da água produzida de poços petrolíferos [dissertação de mestrado]. Sergipe: Departamento de Engenharia e Ciências de Materiais, Universidade Federal de Sergipe; 2010.

2 Leite RA. Avaliação da Tenacidade à fratura de uma junta soldada de um aço inoxidável superduplex com a utilização da proteção catódica [dissertação de mestrado] Porto Alegre: Universidade Federal do Rio Grande do Sul; 2009.

3 Melo CL, Thedy EA, Rocha PS, Almeida AS, Musse AP, The challengesonthe CCGS monitoring in thedevelopmentof Santos BasinPre-saltCluster. Energy Procedia. 2011;4:3394-98.

4 Pardal JM. Aços inoxidáveis super duplex: efeitos dos tratamentos térmicos nas propriedades mecânicas, magnéticas e resistência à corrosão. São Paulo: Blucher Academic; 2012. 341p. São Paulo - SP.

5 Souza EC, Rossittib SM, Rolloa JMDA. Influence of chloride ion concentration and temperature on the electrochemical properties of passive films formed on a superduplex stainless steel. Materials Characterization. 2010;61(2):240-244.

6 Otárola T, Hollner S, Bonnefois B, Anglada M, Coudreuse L, Mateo A. Embrittlement of a superduplex stainless steel in the range of $550-700^{\circ} \mathrm{C}$. Engineering Failure Analysis. 2005;12(6):930-941.

\footnotetext{
* Contribuição técnica ao $69^{\circ}$ Congresso Anual da ABM - Internacional e ao 14ํㅡㄹ ENEMET - Encontro Nacional de Estudantes de Engenharia Metalúrgica, de Materiais e de Minas,21 a 25 de julho de 2014, São Paulo, SP, Brasil.
} 


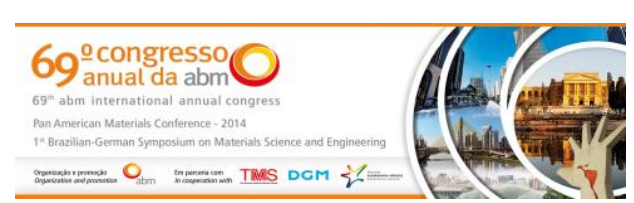

7 Martins M, Casteletti LC. Caracterização Microestrutural do Aço Inoxidável Super Duplex ASTM A890 Grau 6A. In: 12ํ CONAF - Congresso de Fundição; 27-30 set. 2005; São Paulo, Brasil. CONAF; 2005.

8 Martins M. Caracterização microestrutural - mecânica e resistência à corrosão do aço inoxidável super duplex ASTM A890/A890M Grau 6a [tese de doutorado]. São Carlos: Interunidades Ciência e Engenharia de Materiais, Universidade de São Paulo; 2006.

9 ABNT. NBR NM ISO 6506-1: Materiais metálicos - Ensaio de dureza Brinell. Parte 1: método de ensaio. Rio de Janeiro: 2010.

10 ASTM. ASTM G 150-13: Standard Test Method for Electrochemical Critical Pitting Temperature Testing of Stainless Steels. West Conshohocken; 2013.

11 Wolynec S. Técnicas Eletroquímicas em Corrosão. São Paulo: Editora da Universidade de São Paulo; 2003.

12 Fontes TF. Efeito da fase alfa linha nas propriedades mecânicas e de resistência à corrosão do aço inoxidável duplex UR 52N+ [dissertação de mestrado]. São Paulo: Instituto de Pesquisas Energéticas e Nucleares; 2009.

13 Terada M. Estudo da fragilização de $475^{\circ} \mathrm{C}$ nos aços inoxidáveis ferríticos DIN W. Nr. 1.4575 (28\%Cr-4\%Ni-2\%Mo-Nb) e Incoloy MA 956 (20\%Cr-5\%AI-Ti-Y2O3) [dissertação de mestrado]. São Paulo: EscolaPolitécnica da Universidade de São Paulo; 2003.

14 Sérgio Souto Maior Tavares. Título: Aço Inoxidável [apostila de curso]. Fortaleza: Universidade Federal do Ceará.

15 International Molybdenium Association - IMOA. Practical Guidelines for the Fabrication of Duplex Stainless Steels. London: England; 2009. Disponível em: $<\mathrm{http}: / /$ www.imoa.info/media_centre/downloads/practical_guidelines/fabricationseries.php>. Acesso em: 15 de Fevereiro de 2014.

16 Tavares SSM, Terra VF, De Lima Neto P, Matos DE. Corrosion Resistance Evaluation of the UNS S31803 Duplex Stainless Steels Aged at Low Temperatures (350 to $550^{\circ} \mathrm{C}$ ) Using DLEPR Tests. Journal of Materials Science. 2005;40:4025-28.

\footnotetext{
* Contribuição técnica ao 69ำ Congresso Anual da ABM - Internacional e ao 14ํㅡㄹ ENEMET - Encontro Nacional de Estudantes de Engenharia Metalúrgica, de Materiais e de Minas,21 a 25 de julho de 2014, São Paulo, SP, Brasil.
} 